\title{
The potential of rubber and Acacia plantations for forest carbon stocks in Malaysia
}

\begin{abstract}
In Malaysia, the primary forested land change process is due to the establishment of plantations on logged-over forests and areas used for shifting cultivation. While standing carbon stocks of natural forest have been the focus of many studies, reports on the carbon stocks in Acacia and rubber plantations in Malaysia is sparse. Therefore, this article attempts to collate and analyse Malaysian datasets on total carbon stocks for aboveground biomass in the Acacia and rubber plantations by applying the biomass expansion factor for the period from 1990 to 2013. The forest plantations have higher growth rates, and the harvesting waste and residues left behind are significantly more than the natural forests. Therefore, it leads to greater emission compared to the natural forests. Hence, Acacia and rubber plantations were not able to sequester and store carbon at the same amount as the natural forest, which resulted in carbon credit on the forest carbon stock.
\end{abstract}

Keyword: Aboveground biomass; Carbon stock; Malaysia; Natural forests; Plantations 